\title{
A phoneme-grapheme feedback consistency effect
}

\author{
CONRAD PERRY \\ University of Hong Kong, Hong Kong \\ and Macquarie Centre for Cognitive Science, Sydney, Australia
}

\begin{abstract}
Recent studies examining the feedback consistency effecthave been criticized for poor item selection (Peereman, Content, \& Bonin, 1998). In the present study, an experiment was run with a new set of items, in which feedback consistency was manipulated at a phoneme-grapheme level. The results suggested that participants responded faster to feedback-consistent words than to feedback-inconsistent words. This was despite the feedback-consistent and feedback-inconsistent word groups' being matched on many other dimensions, including word frequency and subjective orthographic frequency. These results may differ from those of previous studies, since previous studies in English have measured feedback consistency at the rime-body level.
\end{abstract}

The type of interactivity that exists between different representational levels of cognitive models provides an important constraint on the type of behavior that they can predict. Both the speech recognition model of Norris, McQueen, and Cutler (2000) and the speech production model of Levelt, Roelofs, and Meyer (1999) have no top-down interactivity between different representationallevels; in these two models, activation flows in a strictly bottom-up feedforward manner. The authors of both models made strong claims against the need to add top-down interactivity between representations, given current evidence. Norris et al. argued further that there is no evidence for any top-down interactivity between representations in word reading. This claim contrasts with the computationalimplementation of the word reading model of Coltheart, Rastle, Perry, Langdon, and Ziegler (2001), in which cascaded activation flows in both bottom-up and top-down directions among different representational levels of the model.

Contrary to Norris et al.'s (2000) claims, the feedback consistency effect (e.g., Stone, Vanhoy, \& Van Orden, 1997; Ziegler \& Ferrand, 1998;Ziegler, Montant, \& Jacobs, 1997) has been used as evidence to suggest that the word recognition system is highly interactive, with activation flowing not only from orthography to phonology, but also from phonology to orthography. Studies examining this effect have demonstrated that people respond to words whose rimes can be spelled in many ways more slowly than they do to words whose rimes can be spelled in only one way. It has been hypothesized that this is because words with rimes that can be spelled in many ways (i.e., feedback-inconsistent words) cause activation to feed back from phonology to mul-

This work was supported by an ARC special center grant awarded to Max Coltheart and a UDF grant from the University of Hong Kong. I thank Jo Ziegler for many helpful comments. Correspondence concerning this article should be addressed to C. Perry, Joint Lab for Language and Cognitive Neuroscience, University of Hong Kong, Hong Kong (email: conrad@hkucc.hku.hk). tiple orthographic patterns, whereas words with rimes that can be spelled in only one way cause activation to feed back from phonology to only one orthographic pattern. In addition when activation feeds back to orthographic patterns that differ from the word being responded to, the speed at which the correct activation can build up is slowed, owing to incorrect orthographic patterns' having an inhibitory effect on the correct pattern. This inhibitory effect causes people's responses to be slower.

Recently, some of the results thought to support the feedback consistency effect have been criticized by Peereman, Content, and Bonin (1998), who argued that the words used as stimuli may have been confounded on either subjective orthographic frequency or word frequency. More specifically, Peereman et al. noted that when participants were asked to judge how frequently printed words occurred (subjective orthographic familiarity), the two treatment conditions in Ziegler et al.'s (1997) stimulus set differed on that measure. When a set of words was chosen that was not confounded on that variable and run in a similar experiment, Peereman et al. found no effect of feedback consistency. In addition, Peereman et al. suggested that Stone et al.'s (1997) stimuli may have been confounded on word frequency if measured using the CELEX (Baayen, Piepenbrock, \& van Rijn, 1993) versus the Kučera and Francis (1967) database.

Norris et al. (2000) offered an additional criticism of the feedback consistency effect in general. They argued that feedback-inconsistent words tend to have lower bodyrime frequencies than feedback-consistent words do. That is, the number of times that a given body-rime relationship occurs tends to be less for feedback-inconsistent than for feedback-consistent words. Norris et al. argued that since this factor could be important in predicting reaction times, it could provide an alternative explanation of Stone et al.'s (1997) data.

One reason why previous feedback consistency results may have been difficult to obtain in English is that all stud- 
ies examining the effect at a subsyllabic level have used the rime-body relationship to calculate feedback consistency. ${ }^{1}$ At least in English, this may not provide the strongest manipulation, for two reasons.

First, when spelling, people tend to use spelling-sound and sound-spelling correspondences that are based on small (i.e., grapheme-phoneme and phoneme-grapheme) rather than large sized relationships (which is not to say they do not use large-sized relationships). This can be seen in the study of Perry, Ziegler, and Coltheart (2002a), who found that people typically spelled nonwords by using phonemegrapheme correspondences, rather than larger rime-body correspondences. Thus it appears that when spelling, people tend to use small units. Therefore, a stronger manipulation of feedback consistency might be possible using smallsized rather than rime-body sized relationships.

Second, at least in English, vowels tend to be much more inconsistent than the rimes in which they are embedded. In the analysis of Perry, Ziegler, and Coltheart (2002b), for instance, where counts for all phonemegrapheme relationships were obtained, there were 10 different spellings for the /eI/ vowel (e.g., raid), and that vowel was not unusual. This contrasts with most rimes, which typically have fewer spellings.

A further observation in support of the possibility that the feedback consistency effect might be stronger at a phoneme-grapheme level rather than a rime-body level is that in Stone et al.'s (1997) study, when the reaction times of feedforward-inconsistent words that were also feedback inconsistent were compared with those of feedforwardconsistent words that were feedback inconsistent, no additive effect of feedforward consistency was found. One explanation for this is that if feedback consistency effects occur at a phoneme-grapheme level, this means that words that appear to be feedforward inconsistent but feedback consistent are really also feedback inconsistent. The reason is as follows. If a correspondence is feedforward inconsistent at a grapheme-phoneme level, it will tend to be highly feedback inconsistent at that level. For example, the vowel in the word rasp is feedforward inconsistent at a grapheme-phoneme level but feedback consistent at a rime-body level. However, at a phoneme-grapheme level, the $/ \mathrm{a}: / \rightarrow a$ relationship occurs much less frequently than /a: $/ \rightarrow a r$ (the most common relationship that occurs with the /a:/ phoneme). This means that the vowel in the word gasp is more feedback inconsistent than the vowel in the word harm. Note that the actual measurement of feedback consistency depends on how the phoneme-grapheme relationships are calculated, and this calculation can differ depending on different assumptions that are made (e.g., Perry et al., 2002b). For most correspondences, however, the level of consistency remains very similar, independent of different assumptions that are made.

Since feedback consistency may be measured at a number of levels (Stone et al., 1997), and since the rime-body level may not provide the strongest manipulation, in the present study we examined the effect of feedback consistency at a phoneme-grapheme level. Three groups of words were constructed: a feedforward-consistent group that contained a vowel that was the most common spelling of that vowel $(\mathrm{C}-\mathrm{C})$; a feedforward consistent group that contained a vowel correspondence that was not the most common spelling for that vowel (C-I); and a feedforward irregular vowel group that therefore contained a vowel that was not the most common spelling (I-I). The use of these three groups was intended to reveal whether there would be an effect of feedback consistency at the phonemegrapheme level (C-C vs. C-I) and feedforward irregularity with feedback consistency controlled (C-I vs. I-I).

\section{METHOD}

\section{Participants}

Thirty-six students from a 1st-year psychology course at Macquarie University participated in the experiment in return for course credit. Twenty participated in the lexical decision task. Sixteen gave subjective orthographic frequency judgments for the word set used.

\section{Procedure}

The participants were seated $50 \mathrm{~cm}$ in front of an IBM-compatible computer. They were given verbal instructions about the task, which was lexical decision. They were specifically asked to respond as quickly and as accurately as possible to each stimulus, but to try not to make too many errors. Ten filler items were presented before the 150 experimental trials. The order of the experimental trials was randomized for each participant. Each experimental trial began with a 1,000 -msec presentation of a fixation mark ("*") centered in the middle of the screen. After the 1,000-msec had elapsed, the marker was replaced by the experimental stimulus. The experimental stimulus then remained on the screen until the participant had responded with either the "a" (nonword) or the ";" (word) key.

The stimuli were presented using the Inquisit experimental psychology package in lowercase 14-point Courier font. Reaction times were measured between the onset of the stimulus and the participant's response.

\section{Stimuli}

Three groups of 25 words were used. Across the three groups, the following variables were balanced (i.e., an $F$ test across the three groups had a $p$ value greater than .1) : orthographic neighbors, higher frequency neighbors, body neighbors, frequency, subjective orthographic frequency, and orthographic length. In addition, to try to reduce any variance caused by the feedback consistency of initial consonants, triplets across each group were matched on the first letter and consonant phoneme. Feedback consistency of the vowel (i.e., phoneme-grapheme contingency) was determined from the database of Perry et al. (2002b), as was grapheme-phoneme vowel correspondence frequency. In that study, counts for all phonemegrapheme relationships were calculated from the entire set of monosyllabic words in the CELEX database, using a number of different possible phoneme-grapheme segmentations. The different segmentations were then correlated with results from a word spelling task and further examined in a nonword spelling experiment. The results from the phoneme-grapheme segmentation counts most predictive of human performance are used here. In this study, the -ea grapheme was not used in the feedback-consistent group, since, according to the statistics of Perry et al. (2002b), -ee and -ea graphemes have very similar frequency counts, thus making words with those spellings relatively feedback inconsistent in comparison with words using more dominant graphemes. High and low phoneme-grapheme contingency were operationalized so that high meant the most common spelling for a given vowel phoneme and low meant any other spelling. The individual items appear in the Appendix. A further 75 
nonwords that did not share any orthographic bodies with the words were also used. They had an average of 4.29 letters, 6.61 body neighbors, and 5.41 orthographic neighbors. None were pseudohomophones, and none contained bigrams that did not exist.

\section{Subjective Orthographic Frequency Ratings}

Subjective orthographic frequency ratings were collected in the study by asking participants to write down a rating from 1 to 7 for each of the 75 words, with 1 being extremely infrequent and 7 being extremely frequent. The participants were asked specifically to write down how often they thought the words occurred in printed and not spoken form. In addition, although there were no time constraints, participants were asked not to take too long on each word. The words themselves were printed on a sheet of paper with a box next to them where the rating could be written. A description of the rating system appeared at the top of the sheet. Word order was randomized for each booklet.

\section{Results}

Only word responses were analyzed, since the nonword results were not of theoretical interest. For all participants, incorrect responses were removed from the reaction time analysis. This accounted for $7.07 \%$ of the data. Similarly, for each participant, responses that had latencies 3.0 standard deviations above or below the individual grand mean were considered errors and removed from the analysis. This accounted for $2.07 \%$ of the total number of responses. Mean response latencies and error rates are summarized in Table 1. Individual items and individual item characteristics appear in the Appendix.

An analysis of variance (ANOVA) performed on the subjective frequency ratings showed that they were unlikely to be confounded with any other factors, for there were no significant differences between any of the individual groups either by participants or by items (all $p \mathrm{~s}>.1$ ). This variable was therefore not considered further.

An ANOVA performed on the reaction times of the three different groups was significant by participants $\left[F_{1}(2,38)=7.12, p<.005\right]$, but not quite by items $\left[F_{2}(2,72)=2.65, p=.078\right]$. Individual planned comparisons using two-tailed $t$ tests found that the C-I group had significantly slower reaction times than did the $\mathrm{C}-\mathrm{C}$ group $\left[t_{1}(19)=2.72, p<.05 ; t_{2}(48)=2.04, p<.05\right]$. The I-I group was also significantly slower than the $\mathrm{C}-\mathrm{C}$ group $\left[t_{1}(19)=3.74, p<.005 ; t_{2}(48)=2.28, p<.05\right]$. The C-I and I-I groups were not significantly different (both $t$ s $<$ 1). An analysis of errors showed a similar pattern: The initial ANOVA was significant $\left[F_{1}(2,38)=17.97, p<.001\right.$;

\section{Table 1}

Mean Reaction Times and Standard Errors $(S E)$ for Correct Responses and Percentage of Errors (\% E) for Feedforward Consistent Feedback Consistent (C-C), Feedforward Consistent Feedback Inconsistent (C-I), and Feedforward Irregular Feedback Inconsistent (I-I) words

\begin{tabular}{cccccc}
\hline & \multicolumn{2}{c}{ RT } & & \multicolumn{2}{c}{$\% \mathrm{E}$} \\
\cline { 2 - 3 } \cline { 5 - 6 } Word Type & $M$ & $S E$ & & $M$ & $S E$ \\
\hline C-I & 728 & 22.34 & & 10.80 & 2.73 \\
I-I & 732 & 21.61 & & 7.40 & 2.08 \\
C-C & 676 & 12.01 & & 3.00 & 0.71 \\
\hline
\end{tabular}

$\left.F_{2}(2,72)=3.73, p<.05\right]$, as were both the $\mathrm{C}-\mathrm{I}$ versus $\mathrm{C}-\mathrm{C}\left[t_{1}(19)=5.04, p<.001 ; t_{2}(48)=2.76, p<.01\right]$ and $\mathrm{I}-\mathrm{I}$ versus $\mathrm{C}-\mathrm{C}\left[t_{1}(19)=3.58, p<.005 ; t_{2}(48)=2.00\right.$, $p=.051]$ comparisons. Interestingly, the $\mathrm{C}-\mathrm{I}$ group actually had significantly more errors than did the I-I group by participants $\left[t_{1}(19)=3.19, p<.01 ; t_{2}<1\right]$. Because this result did not even approach significance by items, however, it might simply have been noise, and so it was not considered further.

Since it has been argued that feedback consistency is a continuous rather than a dichotomous measure (e.g., Stone et al., 1997), it might be more appropriate to use a regression analysis of the data, rather than a factorial analysis. Therefore, the data were analyzed further by correlating the vowel contingency value of each word (i.e., a continuous feedback consistency measure, calculated for each vowel spelling by dividing the number of times a given vowel spelling occurs with the number of times all spellings of that vowel occur) with the reaction time and error data. The results showed that there was a significant negative correlation between vowel contingency and reaction time $(r=-.25, p<.05)$, and a similar correlation between vowel contingency and error rate $(r=-.23, p<$ $.05)$. These two correlations suggest that words with lower vowel contingencies had slower response latencies and produced more errors.

\section{Norris et al. Analysis}

One potential problem with the interpretation of the results of this experiment is that they may not have been due to feedback consistency, but rather to the frequency of the spelling-sound correspondence (i.e., the frequency at which a given vowel spelling-sound correspondence occurs; see Norris et al., 2000). As can be seen from the mean statistics reported in the Appendix, the stimuli of this experiment were confounded on this measure across groups. However, it is possible to examine the question by (1) choosing items from the $\mathrm{C}-\mathrm{I}$ and $\mathrm{C}-\mathrm{C}$ groups and using a factorial approach, and (2) using a correlational approach with the entire dataset.

In terms of the factorial approach, a set of items was selected that was balanced on the frequency of the vowel correspondences. This was done by removing high vowel correspondence frequency items from the $\mathrm{C}-\mathrm{C}$ group (all items with a vowel correspondence frequency larger than 300), and low vowel correspondence frequency items from the C-I group (all items with a vowel correspondence frequency less than 100). This left two sets of items (13 items in the $\mathrm{C}-\mathrm{C}$ group, and 12 items in the $\mathrm{C}-\mathrm{I}$ group) that were not significantly different (all $p s>.1$ ) on any of the measures initially balanced in the data set and were also not significantly different on vowel correspondence frequency. The absolute magnitude of the feedback consistency effect was slightly larger than that for the entire data set (70.08 msec), although because of the smaller number of items, the effect just failed to reach significance by items in the reaction time analysis [RTs, $t_{1}(19)=2.25, p<.05$, $t_{2}(23)=1.87, p=.74$; errors, $t_{1}(19)=4.92, p<.001$, $\left.t_{2}(23)=2.44, p<.05\right]$. 
To examine the effect of vowel correspondencefrequency in terms of a correlational analysis, all of the items in the data set were used. The results showed that the frequency of the vowel correspondence was not significantly correlated with either reaction time $(r=-.13, p>.05)$ or error rate $(r=-.10, p>.05)$.

Overall, the results of this experiment show that a feedback consistency effect, at least at the phoneme-grapheme level, can be found in a normal lexical decision task. This result occurred despite the fact that many other factors, including subjective orthographic frequency, were controlled. Furthermore, when an analysis of a potentially confounding factor (vowel correspondence frequency) was performed, the results showed that the feedback consistency effect still existed once that factor was controlled, and that no significanteffects of the confounding factor could be found. Interestingly, even though a feedback consistency effect was found, no effect of feedforward regularity was found.

\section{DISCUSSION}

The feedback consistency effect suggests that, when one is reading, there is much interactivity between orthography and phonology. Two of the studies that have reported a feedback consistency effect have been criticized for not being replicable once subjective orthographic frequency and CELEX frequency have been accounted for (Peereman et al., 1998), however.

In the experiment reported here, a feedback consistency effect was found even with a number of variables, including those under dispute in previous studies, controlled. It therefore provides an existence refutation of the claim that feedback consistency effects do not exist or are too small to be found in lexical decision tasks.

One reason why this study may have yielded a result different from those found previously was that instead of manipulating feedback consistency at a body-rime level, it was manipulated at a phoneme-grapheme level. This was done because a manipulation at a rime-body level may be weaker than a manipulation at a vowel level. One reason for this is that it is possible to get a more extreme comparison at a phoneme-grapheme level than at a rimebody level, since the difference between common and uncommon grapheme spellings is often much more than common and uncommon body spellings.

Furthermore, when the results were analyzed with the potentially confounded vowel grapheme-phoneme frequency factor excluded, essentially the same results were found. No significanteffects of vowel grapheme-phoneme frequency were found, however. Note that this is not the only evidence suggesting that feedback consistency is the cause of slower responses, rather than grapheme-phoneme frequency. In a commentary by Coltheart and Coltheart (1997) on the work of Van Orden, Johnston, and Hale (1988), it was noted that the distribution of errors made by participants in a semantic classification task was not homogeneous. Rather, a number of items seemed to produce extremely high error rates. This was particularly so for the
EE/EA correspondence (e.g., SHEAP/SHEEP). According to the database of Perry et al. (2002b), such a correspondence is of very high frequency, but also very feedback inconsistent.

The phoneme-grapheme explanation also provides one possible explanation of why Stone et al. (1997) found no effect of feedback consistency on words that were feedforward inconsistent. The reason for this is that, when measured at a phoneme-grapheme level, words that have irregular grapheme-phoneme translations are typically very feedback inconsistent. Thus what was considered to be feedback consistent by Stone et al. was actually also feedback inconsistent at a phoneme-grapheme level. Thus, if the strongest manipulation of subsyllabic sized feedback effects in English is at the phoneme-grapheme level-and this study shows it does provide a strong manipulation-then Stone et al. may have been comparing an inhibitory effect of feedback consistency in both groups, thus making differences harder to find.

One aspect of the data that might make the interpretation of the results given here seem problematic is that as in many other lexical decision studies, no effect of feedforward regularity was found (see Berent, 1998, for a review). If this null effect is interpreted as reflecting the absence of phonology in the experiment, it is difficult to see how a feedback consistency effect could have been obtained. However, counter to this interpretation, Berent has argued that the regularity effect is only one marker of the generation of phonology in lexical decision tasks, and therefore that the failure to find a regularity effect does not necessarily preclude the possibility that phonology is generated and used. In support of this argument, Berent showed that an effect of phonological priming could be found in a lexical decision task, despite a null effect of regularity's being found. She argued that such a result shows that phonology is used in lexical decision tasks, and that the reason that no regularity effect was found was that the regularity effect arises only late in the time course of the generation of phonology.

Overall, these results add to others that suggest there is strong interactivity between phonology and orthography during reading. Feedback consistency effects have now been found at a subsyllabic level (this study), at a wholeword level (Pexman \& Lupker, 1999; Ziegler, Jacobs, \& Klüppel, 2001), and in semantics (Hino \& Lupker, 1996). Together, these results support the possibility that feedback effects are representative of a general principle of the reading system.

\section{REFERENCES}

BaAyen, R. H., Piepenbrock, R. \& van Rujn, H. (1993). The CELEX lexical database (CD-ROM). Philadelphia: University of Pennsylvania, Linguistic Data Consortium.

Berent, I. (1998). Phonological priming in the lexical decision task: Regularity effects are not necessary evidence for assembly. Journal of Experimental Psychology: Human Perception \& Performance, 23, 1727-1742.

Coltheart, M., \& Coltheart, V. (1997). Reading comprehension is not exclusively reliant upon phonological representation. Cognitive Neuropsychology, 14, 167-175. 
Coltheart, M., Rastle, K., Perry, C., Langdon, R. \& Ziegler, J. C. (2001). DRC: A dual route cascaded model of word recognition and reading aloud. Psychological Review, 108, 204-256.

Hino, Y., \& LuPKER, S. J. (1996). Effects of polysemy in lexical decision and naming: An alternative to lexical access accounts. Journal of Experimental Psychology: Human Perception \& Performance, 24, $1162-1187$

KuČera, H., \& Francis, W. N. (1967). Computational analysis of present-day American English. Providence, RI: Brown University Press.

Levelt, W. J., Roelofs, A., Meyer, A. S. (1999). A theory of lexical access in speech production. Behavioral \& Brain Sciences, 22, 1-38.

Norris, D., McQueen, J. M., \& Cutler, A. (2000) Merging information in speech recognition: Feedback is never necessary. Behavioral \& Brain Sciences, 23, 299-325.

Peereman, R, Content, A., \& Bonin, P. (1998). Is perception a twoway street? The case of feedback consistency in visual word recognition. Journal of Memory \& Language, 39, 151-174.

Perry, C., Ziegler, J. C., \& Coltheart, M. (2002a). A dissociation between orthographic awareness and spelling production. Applied Psycholinguistics, 23, 43-73.

Perry, C., Ziegler, J. C., \& Coltheart, M. (2002b). How predictable is spelling? Developing and testing metrics of phoneme-grapheme contingency. Quarterly Journal of Experimental Psychology, 55A, 897-915.

Pexman, P. M., \& Lupker, S. J. (1999). Ambiguity and visual word recognition: Can feedback explain both homophone and polysemy effects? Canadian Journal of Experimental Psychology, 53, 323-334. Stone, G. O., Vanhoy, M. D., \& Van Orden, G. C. (1997). Perception is a two-way street: Feedforward and feedback phonology in visual word recognition. Journal of Memory \& Language, 36, 337-359.

Van Orden, G. C., Johnston, J. C., \& Hale, B. L. (1988). Word identification in reading proceeds from spelling to sound to meaning. Journal of Experimental Psychology: Learning, Memory, \& Cognition, 14, 371-386.

Ziegler, J. C., \& Ferrand, L. (1998). Orthography shapes the perception of speech: The consistency effect in auditory word recognition. Psychonomic Bulletin \& Review, 5, 683-689.

Ziegler, J. C., Jacobs, A. M., \& KlüPpel, D. (2001). Pseudohomophone effects in lexical decision: Still a challenge for current word recognition models. Journal of Experimental Psychology: Human Perception \& Performance, 27, 547-559.

Ziegler, J. C., Montant, M., \& Jacobs, A. M. (1997). The feedback consistency effect in lexical decision and naming. Journal of Memory \& Language, 37, 533-554.

Ziegler, J. C., \& VAN Orden, G. C. (2000). Feedback consistency effects. Brain \& Behavioral Sciences, 23, 351-352.

\section{NOTE}

1. The situation in French is different and far from clear. Peereman et al. (1998) suggested that there was no effect of feedback consistency at a phoneme-grapheme level. However, Ziegler and Van Orden (2000) reanalyzed their data by removing items with extremely high error rates that would typically be removed in other studies. Having done so, Ziegler and Van Orden found some evidence for a feedback consistency effect in French at a phoneme-grapheme level.

APPENDIX

Individual Items and Item Statistics

\begin{tabular}{|c|c|c|c|c|c|c|c|c|c|c|c|}
\hline Word & $\mathrm{N}$ & HFN & Freq & $\mathrm{BN}$ & Len & Con Ratio & PGC & GPC Count & Fam & RTs & $\% \mathrm{E}$ \\
\hline \multicolumn{12}{|l|}{ C-I } \\
\hline bloat & 3 & 3 & 2 & 11 & 5 & 1 & 0.25 & 108 & 3.19 & 769 & 5 \\
\hline brute & 0 & 0 & 91 & 7 & 5 & 1 & 0.13 & 39 & 3.19 & 814 & 10 \\
\hline chirp & 1 & 1 & 5 & 1 & 5 & 1 & 0.25 & 72 & 2.94 & 744 & 5 \\
\hline cloak & 2 & 1 & 123 & 4 & 5 & 1 & 0.25 & 108 & 3.31 & 659 & 5 \\
\hline coach & 4 & 0 & 507 & 4 & 5 & 1 & 0.25 & 108 & 4.81 & 700 & 10 \\
\hline deem & 5 & 4 & 14 & 3 & 4 & 1 & 0.38 & 195 & 3.44 & 1034 & 35 \\
\hline drawl & 5 & 3 & 25 & 10 & 5 & 1 & 0.19 & 68 & 2.63 & 813 & 30 \\
\hline lirt & 1 & 1 & 24 & 7 & 5 & 1 & 0.25 & 72 & 4.38 & 632 & 0 \\
\hline leece & 0 & 0 & 15 & 2 & 6 & 1 & 0.38 & 195 & 3.06 & 687 & 5 \\
\hline oam & 4 & 1 & 122 & 3 & 4 & 1 & 0.25 & 108 & 4.00 & 689 & 5 \\
\hline greed & 7 & 4 & 152 & 20 & 5 & 1 & 0.38 & 195 & 5.00 & 582 & 0 \\
\hline herb & 5 & 4 & 172 & 2 & 4 & 1 & 0.26 & 74 & 4.19 & 644 & 5 \\
\hline hawk & 5 & 0 & 239 & 3 & 4 & 1 & 0.19 & 68 & 3.75 & 667 & 0 \\
\hline keel & 6 & 6 & 40 & 10 & 4 & 1 & 0.38 & 195 & 2.63 & 815 & 30 \\
\hline maim & 3 & 3 & 12 & 3 & 4 & 1 & 0.26 & 150 & 2.81 & 792 & 40 \\
\hline moat & 7 & 6 & 36 & 11 & 4 & 1 & 0.25 & 108 & 2.69 & 949 & 20 \\
\hline nerve & 2 & 1 & 257 & 4 & 5 & 1 & 0.26 & 74 & 4.50 & 592 & 0 \\
\hline reef & 4 & 2 & 123 & 2 & 4 & 1 & 0.38 & 195 & 4.19 & 642 & 0 \\
\hline soap & 6 & 0 & 366 & 1 & 4 & 1 & 0.25 & 108 & 4.88 & 674 & 0 \\
\hline serve & 3 & 0 & 1189 & 4 & 5 & 1 & 0.26 & 74 & 4.63 & 680 & 5 \\
\hline thirst & 0 & 0 & 107 & 2 & 6 & 1 & 0.25 & 72 & 5.19 & 597 & 0 \\
\hline verse & 3 & 0 & 178 & 3 & 5 & 1 & 0.26 & 74 & 4.06 & 670 & 0 \\
\hline fraud & 1 & 1 & 120 & 2 & 5 & 1 & 0.14 & 51 & 4.38 & 732 & 20 \\
\hline bail & 15 & 8 & 185 & 19 & 4 & 0.95 & 0.26 & 150 & 3.63 & 723 & 0 \\
\hline shirk & 4 & 3 & 2 & 6 & 5 & 1 & 0.25 & 72 & 2.50 & 892 & 40 \\
\hline
\end{tabular}


APPENDIX (Continued)

\begin{tabular}{|c|c|c|c|c|c|c|c|c|c|c|c|}
\hline Word & $\mathrm{N}$ & HFN & Freq & $\mathrm{BN}$ & Len & Con Ratio & PGC & GPC Count & Fam & RTs & $\% \mathrm{E}$ \\
\hline \multicolumn{12}{|l|}{ I-I } \\
\hline butch & 6 & 3 & 100 & 5 & 5 & 0.2 & 0.29 & 22 & 3.25 & 776 & 0 \\
\hline bask & 12 & 9 & 14 & 6 & 4 & 1 & 0.39 & 124 & 2.56 & 822 & 10 \\
\hline chalk & 0 & 0 & 174 & 5 & 5 & 1 & 0.05 & 18 & 3.81 & 645 & 5 \\
\hline cough & 8 & 2 & 227 & 13 & 5 & 0.15 & 0.01 & 7 & 4.88 & 727 & 0 \\
\hline calf & 4 & 3 & 186 & 2 & 4 & 1 & 0.07 & 124 & 3.50 & 724 & 0 \\
\hline dough & 6 & 3 & 184 & 13 & 5 & 0.077 & 0.00 & 1 & 3.19 & 666 & 0 \\
\hline dread & 4 & 2 & 170 & 16 & 5 & 0.63 & 0.07 & 41 & 4.31 & 726 & 0 \\
\hline fete & 1 & 1 & 26 & 1 & 4 & 1 & 0.01 & 5 & 3.13 & 987 & 40 \\
\hline fiend & 1 & 1 & 22 & 2 & 5 & 0.5 & 0.08 & 41 & 3.06 & 992 & 25 \\
\hline folk & 3 & 0 & 307 & 2 & 4 & 1 & 0.01 & 4 & 3.31 & 704 & 5 \\
\hline ghost & 0 & 0 & 351 & 8 & 5 & 0.5 & 0.17 & 75 & 4.31 & 616 & 0 \\
\hline height & 1 & 1 & 616 & 4 & 6 & 0.25 & 0.01 & 2 & 4.94 & 605 & 5 \\
\hline halve & 3 & 1 & 27 & 4 & 5 & 0.5 & 0.05 & 23 & 4.44 & 796 & 10 \\
\hline keys & 3 & 0 & 295 & 4 & 4 & 0.25 & 0.05 & 3 & 5.00 & 646 & 0 \\
\hline monk & 4 & 1 & 70 & 4 & 4 & 0.25 & 0.09 & 20 & 3.19 & 674 & 0 \\
\hline mauve & 0 & 0 & 81 & 1 & 5 & 1 & 0.00 & 1 & 2.44 & 781 & 25 \\
\hline niche & 0 & 0 & 67 & 2 & 5 & 0.5 & 0.01 & 6 & 3.56 & 820 & 20 \\
\hline rasp & 5 & 4 & 9 & 6 & 4 & 0.83 & 0.39 & 124 & 2.13 & 864 & 15 \\
\hline soup & 3 & 2 & 362 & 4 & 4 & 0.75 & 0.08 & 25 & 4.81 & 655 & 0 \\
\hline swamp & 2 & 1 & 86 & 15 & 5 & 0.067 & 0.10 & 57 & 3.25 & 648 & 5 \\
\hline thread & 1 & 1 & 198 & 16 & 6 & 0.63 & 0.07 & 41 & 4.13 & 602 & 0 \\
\hline vault & 2 & 1 & 58 & 2 & 5 & 1 & 0.14 & 51 & 3.75 & 689 & 0 \\
\hline flown & 4 & 1 & 152 & 17 & 5 & 0.53 & 0.04 & 16 & 3.31 & 735 & 10 \\
\hline bull & 16 & 6 & 461 & 12 & 4 & 0.25 & 0.29 & 22 & 3.63 & 605 & 0 \\
\hline shove & 4 & 4 & 75 & 20 & 5 & 0.2 & 0.03 & 17 & 4.06 & 802 & 10 \\
\hline \multicolumn{12}{|l|}{$\mathrm{C}-\mathrm{C}$} \\
\hline boost & 2 & 0 & 130 & 2 & 5 & 1 & 0.67 & 199 & 3.88 & 734 & 0 \\
\hline blink & 5 & 3 & 68 & 19 & 5 & 1 & 0.96 & 831 & 3.75 & 654 & 5 \\
\hline chess & 4 & 1 & 264 & 10 & 5 & 1 & 0.90 & 510 & 3.88 & 669 & 5 \\
\hline cliff & 0 & 0 & 294 & 8 & 5 & 1 & 0.96 & 831 & 4.00 & 622 & 5 \\
\hline coil & 10 & 7 & 59 & 9 & 4 & 1 & 1.00 & 66 & 3.31 & 671 & 0 \\
\hline dusk & 9 & 2 & 268 & 6 & 4 & 1 & 0.92 & 620 & 3.69 & 718 & 5 \\
\hline dope & 15 & 9 & 69 & 12 & 4 & 1 & 0.52 & 227 & 3.56 & 778 & 5 \\
\hline foil & 10 & 5 & 79 & 9 & 4 & 1 & 1.00 & 66 & 4.06 & 643 & 0 \\
\hline frisk & 1 & 1 & 6 & 4 & 5 & 1 & 0.96 & 831 & 2.69 & 743 & 15 \\
\hline frame & 1 & 0 & 480 & 12 & 5 & 1 & 0.64 & 368 & 4.75 & 626 & 0 \\
\hline grime & 3 & 2 & 17 & 11 & 5 & 1 & 0.80 & 294 & 3.31 & 748 & 5 \\
\hline hoist & 2 & 1 & 28 & 3 & 5 & 1 & 1.00 & 66 & 2.75 & 662 & 0 \\
\hline hike & 8 & 6 & 45 & 9 & 4 & 1 & 0.80 & 294 & 3.69 & 607 & 0 \\
\hline kilt & 9 & 5 & 26 & 10 & 4 & 1 & 0.96 & 831 & 2.56 & 821 & 5 \\
\hline moist & 2 & 0 & 143 & 3 & 5 & 1 & 1.00 & 66 & 4.31 & 571 & 5 \\
\hline mince & 2 & 1 & 51 & 5 & 5 & 1 & 0.96 & 831 & 3.81 & 676 & 5 \\
\hline noun & 2 & 2 & 18 & 1 & 4 & 1 & 0.76 & 120 & 3.94 & 715 & 0 \\
\hline ridge & 1 & 0 & 288 & 4 & 5 & 1 & 0.96 & 831 & 3.56 & 703 & 5 \\
\hline slope & 2 & 0 & 336 & 12 & 5 & 1 & 0.52 & 227 & 3.88 & 697 & 0 \\
\hline stroke & 3 & 1 & 351 & 12 & 6 & 1 & 0.52 & 227 & 4.19 & 634 & 0 \\
\hline theft & 0 & 0 & 136 & 6 & 5 & 1 & 0.90 & 510 & 5.50 & 637 & 5 \\
\hline void & 0 & 0 & 102 & 1 & 4 & 1 & 1.00 & 66 & 3.44 & 707 & 0 \\
\hline fridge & 2 & 2 & 70 & 4 & 6 & 1 & 0.96 & 831 & 4.50 & 630 & 0 \\
\hline bride & 3 & 1 & 187 & 13 & 5 & 1 & 0.80 & 294 & 4.81 & 637 & 5 \\
\hline shelf & 2 & 1 & 246 & 3 & 5 & 1 & 0.90 & 510 & 4.31 & 594 & 0 \\
\hline \multicolumn{12}{|l|}{ Average } \\
\hline $\mathrm{C}-\mathrm{I}$ & 3.84 & 2.08 & 164 & 5.76 & 4.68 & .998 & .26 & 109 & 3.76 & 728 & 10.8 \\
\hline I-I & 3.72 & 1.88 & 173 & 7.36 & 4.72 & .56 & .10 & 35 & 3.68 & 732 & 7.4 \\
\hline $\mathrm{C}-\mathrm{C}$ & 3.92 & 2.00 & 150 & 7.52 & 4.76 & 1.00 & .85 & 422 & 3.85 & 676 & 3.0 \\
\hline
\end{tabular}

Note-C-I, feedforward consistent feedback inconsistent; I-I, feedforward irregular feedback inconsistent; C-C, feedforward consistent feedback consistent; N, orthographic neighbors; HFN, higher frequency orthographic neighbors; Freq, CELEX frequency; BN, body neighbors; Len, word length; Con ratio, consistency ratio; PGC, phoneme-grapheme contingency; GPC Count, grapheme-phoneme count; Fam, Subjective orthographic familiarity; RTs, reaction times; \% $\mathrm{E}$, percent error.

(Manuscript received May 8, 2001;

revision accepted for publication March 14, 2002.) 